\title{
Pharmaceutical Management of Trigeminal Neuralgia in the Elderly
}

\author{
M. A. E.-M. Oomens ${ }^{1}$ - T. Forouzanfar ${ }^{1}$
}

Published online: 4 September 2015

(c) The Author(s) 2015. This article is published with open access at Springerlink.com

\begin{abstract}
Classical trigeminal neuralgia (CTN) is a severe neuropathic pain in the distribution of one or more branches of the trigeminal nerve, which occurs in recurrent episodes, causing deterioration in quality of life, affecting everyday habits and inducing severe disability. The aim of this review is to give an overview of the current literature on pharmaceutical treatment options for CTN in the elderly. The first-line treatment for the management of CTN in adults is an antiepileptic-carbamazepine or oxcarbazepine. There is a lack of research on the use of antiepileptics in the elderly. This is a deficiency, as the use of antiepileptics raises a number of problems due to the polypharmacotherapy common in older patients. This can induce drug interactions due to co-morbidities and changes in pharmacokinetics and pharmacodynamics. Furthermore, the side effects of carbamazepine include central nervous system disturbances, such as a lack of balance, dizziness, somnolence, renal dysfunction and cardiac arrhythmias, which are poorly tolerated by the elderly. Unfortunately, the efficacy and safety of alternative treatment options have not been systematically evaluated. On the basis of the current literature, it is not possible to give an evidencebased recommendation for first-line pharmaceutical management of CTN specifically for the elderly.
\end{abstract}

M. A. E.-M. Oomens

marjolijnoomens@hotmail.com; m.oomens@vumc.nl

T. Forouzanfar

t.forouzanfar@vumc.nl

1 Department of Oral and Maxillofacial Surgery/Oral Pathology, VU University Medical Center, P.O. Box 7057, 1007 MB Amsterdam, The Netherlands

\section{Key Points}

Data concerning pharmaceutical treatment for trigeminal neuralgia in the elderly are lacking in the literature, although the incidence increases with advancing age.

Carbamazepine or oxcarbazepine are considered gold-standard treatments for symptoms of trigeminal neuralgia. They have proven to be effective but need to be titrated up slowly because they cause significant side effects, especially to the central nervous system.

\section{Introduction}

In the primary care sector, diagnosis and initial management of orofacial pain are often performed by family doctors and dentists [1]. Trigeminal neuralgia (TN) is a specific diagnosis based on clinical findings, a thorough clinical history and an examination [2]. A multidisciplinary team should manage patients with complicated facial pain [1]. According to the International classification of headache disorders, third edition (ICHD-3), TN is defined as a disorder characterized by recurrent, unilateral, brief, electric shock-like pains, abrupt in onset and termination, limited to the distribution of one or more divisions of the trigeminal nerve and triggered by innocuous stimuli [3]. The annual overall incidence of $\mathrm{TN}$ ranges from 12.6/ 100,000 to $27 / 100,000$ people per year, with an increase in the incidence with advancing age [4]. The mechanism of $\mathrm{TN}$ is described as hyperexcitability of trigeminal root 
fibres near the entry zone into the pons because of mechanical compression (vascular or tumorous) or inflammatory demyelination (multiple sclerosis). Empirical evidence has indicated that vascular compression of the trigeminal nerve root is associated with TN in about $95 \%$ of patients [5]. Magnetic resonance imaging (MRI) studies have given more insights into the pathogenesis of TN. Trigeminal nerve microstructure abnormalities can be identified with new MRI techniques together with trigeminal tractography. Demyelination without significant axonal injury seems to be an important factor in the pathogenesis of TN. Furthermore, there seems to be a state of maintained sensitization of trigeminal nociceptive systems in the brain. Antiepileptic drugs are thought to work in the treatment of TN by blocking voltage-sensitive sodium channels, making brain cells less excitable [6]. Also, grey-matter volume reduction has been found in the primary and secondary somatosensory cortices of $\mathrm{TN}$ patients [4, 7].

TN can be divided into symptomatic TN (STN) and classical (idiopathic) TN (CTN) [3]. STN can be classified by causative or contributing factors, as proposed by Eller et al. [8]-for example, trigeminal neuropathic pain resulting from multiple sclerosis plaques or tumours. Unfortunately, most TN is idiopathic, and the aetiology is not clear.

The guidelines on pharmaceutical TN management published by the American Academy of Neurology (AAN) and the European Federation of Neurological Societies (EFNS) recommend carbamazepine (CBZ; 200-1200 mg/day) or oxcarbazepine (OXC; 600-1800 mg/day) as first-line therapy [9]. Patients unresponsive to $\mathrm{CBZ}$ or OXC should be referred for add-on therapy with lamotrigine or surgery. Elderly patients (defined as persons aged 60 years or older) often present with a number of co-morbid and age-related conditions, which often require polypharmacy. Antiepileptics have wellknown interactions with other drugs. Therefore, it is a challenge to establish a medical treatment for CTN in the elderly without inducing changes in pharmacodynamics and pharmacokinetics, and without causing safety problems.

The aim of this review is to give an overview of the currently available literature on the pharmaceutical management of CTN patients, with a focus on the elderly.

\section{Materials and Methods}

\subsection{Inclusion and Exclusion Criteria}

The studies included in this review were all double-blind, randomized, controlled trials (RCTs) involving non-surgical treatment of CTN. The review excluded articles on
STN, articles not available in English and non-RCT study designs.

\subsection{Outcome Measures}

Pain relief, defined as decreased frequency and decreased intensity of painful paroxysms, was regarded as the primary outcome. Secondary outcome measures were side effects.

\subsection{Literature Searches}

To identify eligible studies, Medline, Embase and Clinicaltrials.gov were searched with the MeSH term 'trigeminal neuralgia'. The search was restricted to RCTs, clinical trials and English-language articles.

\subsection{Data Collection and Analysis}

The titles and abstracts of the articles were screened, and the two authors of the review (MO and TF) decided which articles were eligible for inclusion. Information on the numbers of participants, length of follow-up and outcome measures was extracted from each article, using a data extraction form.

\subsection{Assessment of Risks of Bias}

The risks of bias in each trial were assessed by scoring the security of randomization, allocation concealment, comparability of groups at baseline, double blinding and handling of dropouts. In cases of uncertainty, the authors of the relevant article were contacted whenever possible.

\section{Results}

\subsection{Literature Searches}

The literature search resulted in 171 relevant studies. After review of the abstracts, 18 articles involving non-surgical treatment of CTN were identified. Of these, six articles assessed antiepileptic drugs and 12 investigated nonantiepileptic drugs (Fig. 1).

\subsection{Study Descriptions}

An overview of all included studies is given in Table 1 . The four studies investigating the effectiveness of CBZ, all published before 1970, showed that CBZ reduced both the frequency and the intensity of painful paroxysms in $76 \%$ of included patients [10-13]. A total of 165 patients were included [mean age 58 years (range 34-84)], and there was 
Fig. 1 Flowchart of article selection. i.n. intranasal application, $m$. mucosal application, s.c. subcutaneous application

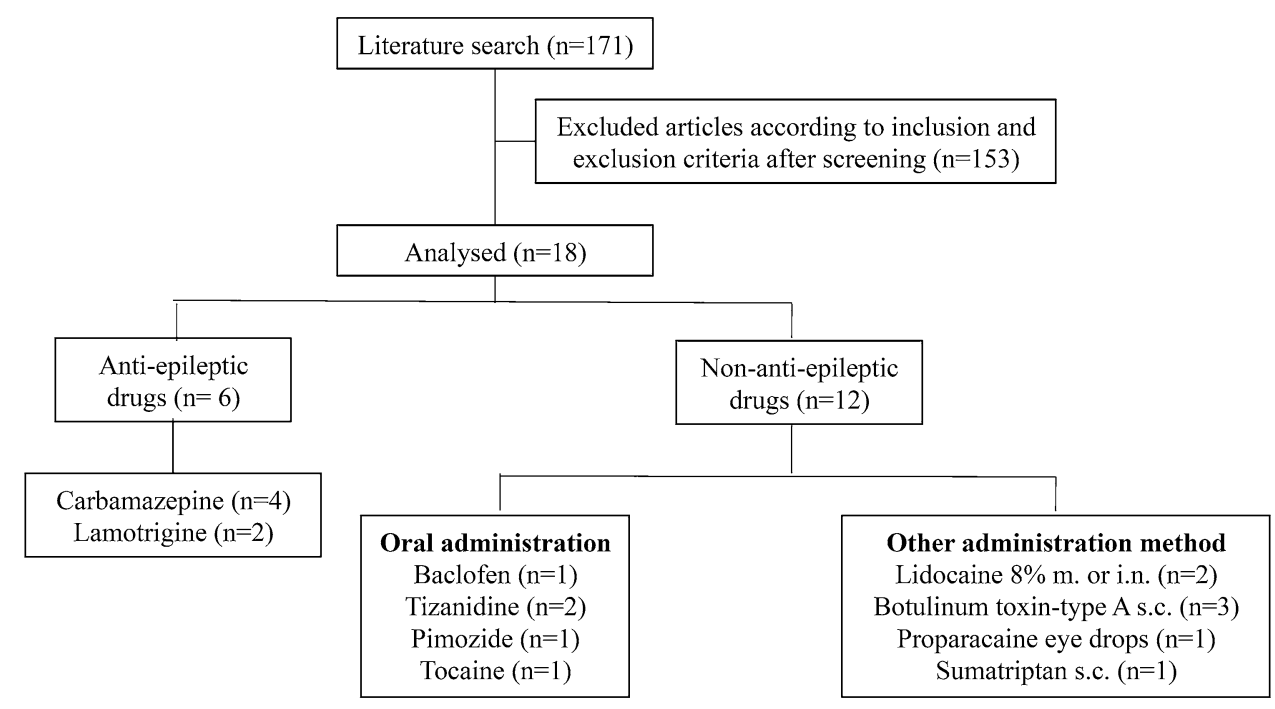

a mean follow-up of 23 months (range 1-46). CBZ dosages ranged from 100 to $2400 \mathrm{mg} /$ day. Side effects of drowsiness, constipation, vertigo, nausea and vomiting, and a rash were described.

Lamotrigine 200-400 mg as add-on therapy was shown to be an effective and safe treatment, in comparison with CBZ alone, for management of $\mathrm{TN}[14,15]$ in $67 \%$ of included patients with a mean age of 63 years (range 44-84). The reported side effects were headache, dizziness and a skin rash.

Some non-antiepileptics, administered orally, have been studied in single trials. Tizanidine $12-18 \mathrm{mg}$ showed no greater effectiveness than CBZ or placebo in 22 patients, with response rates of $56 \%$ for tizanidine, $66 \%$ for CBZ and $40 \%$ for placebo $[16,17]$. Baclofen was superior to placebo in reducing the number of painful paroxysms, with a $70 \%$ response rate in 10 patients with a mean age of 64 years (range 36-77) [18]. In a small group of 12 patients, tocainide was as effective as CBZ in reducing the frequency and severity of pain attacks on a Visual Analogue Scale (VAS), with a response rate of $75 \%$ [19]. Pimozide was even more effective than CBZ in a single trial including 48 patients, with a response rate of $100 \%$ for pimozide versus $56 \%$ for CBZ [20]. The reported side effects were physical and mental retardation, hand tremors and memory impairment in $83 \%$ of the pimozide group. Drugs with local administration have been studied in single trials as well. Topical ophthalmic anaesthesia (proparacaine) was not effective in a single placebo-controlled trial in 47 patients [21]. Botulinum toxin (BTX) type A, administered subcutaneously, proved to be effective (with a $50 \%$ response rate, defined as a decrease in the VAS score of $>50 \%$ ) in three placebo-controlled trials, which included a total of 102 patients with a mean age of 57 years (range 30-88) [22-24]. The reported side effects were transient, such as facial asymmetry, haematoma or oedema. Sumatriptan, administered subcutaneously, was more effective than placebo (response rate $83 \%$ ) in a single trial in a small group of 24 patients [25]. Lidocaine $8 \%$ applied on the mucosa or administered via the intranasal route was effective in $85 \%$ of 49 patients in two placebo-controlled trials, but the effect diminished after approximately $3 \mathrm{~h}[26,27]$.

The studies included in this review included a total of 521 patients with a mean age of 60 years (range 20-88). None of the studies included more than 100 patients. Follow-up periods ranged from 1 week to 46 months.

\subsection{Quality Assessment}

All articles were assessed for risks of bias on the basis of the criteria shown in Table 2. The method of randomization was not clear in many of the included studies. In over half of the included studies, the method of allocation concealment was not clear. All articles, except for one, described handling of dropouts and the reasons for dropout.

\subsection{Statistical Analysis}

Because of the non-homogeneity of the studies' interventions, no pooling of data was possible.

\section{Discussion}

The aim of this review was to give an overview of the current pharmaceutical management of CTN patients, with a focus on the elderly. Overall, the mean age of the patients included in the trials was 60 years. In general, clinical trials tend to exclude patients with co-morbidities and concomitant therapies. Unfortunately, there were no 


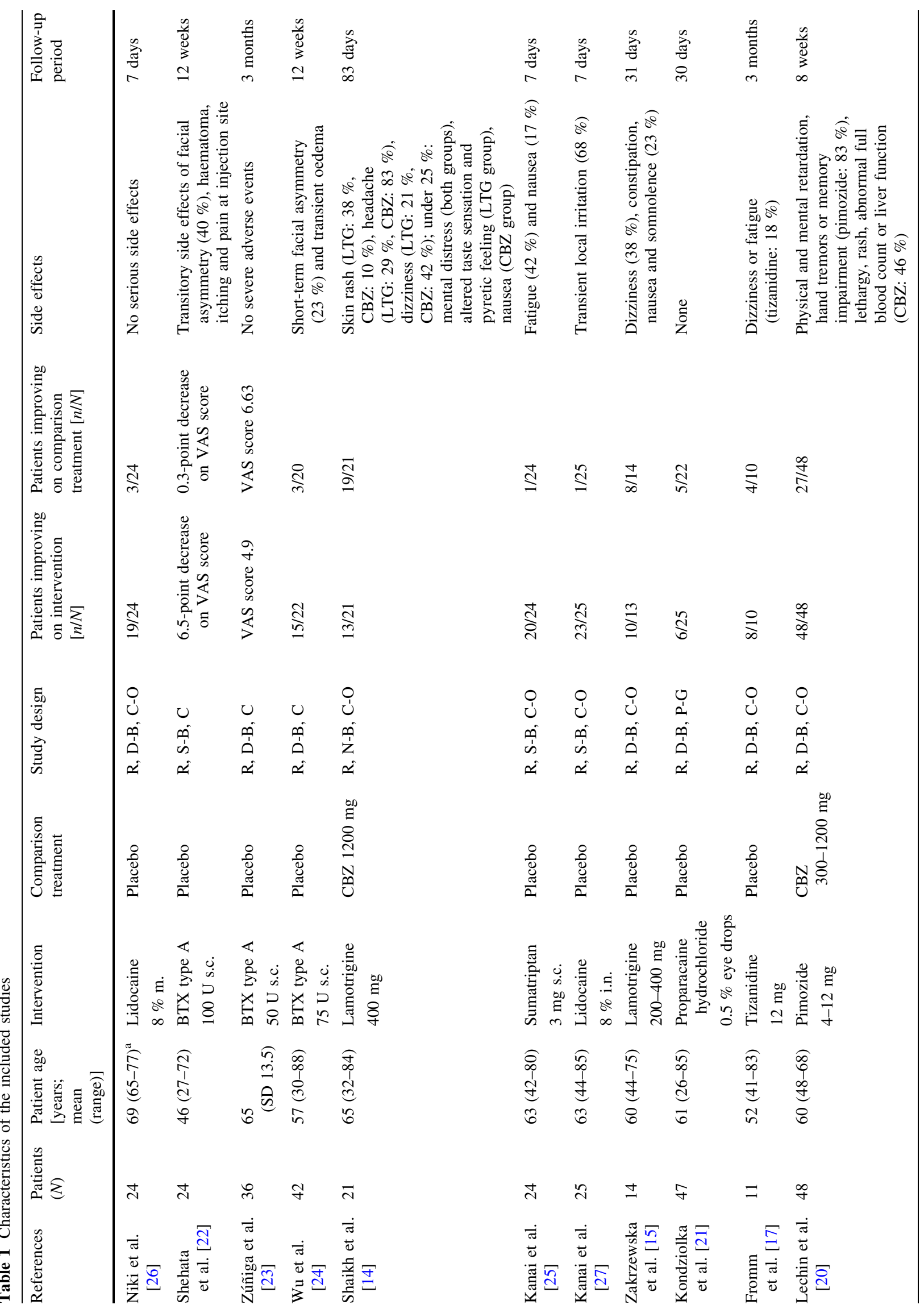




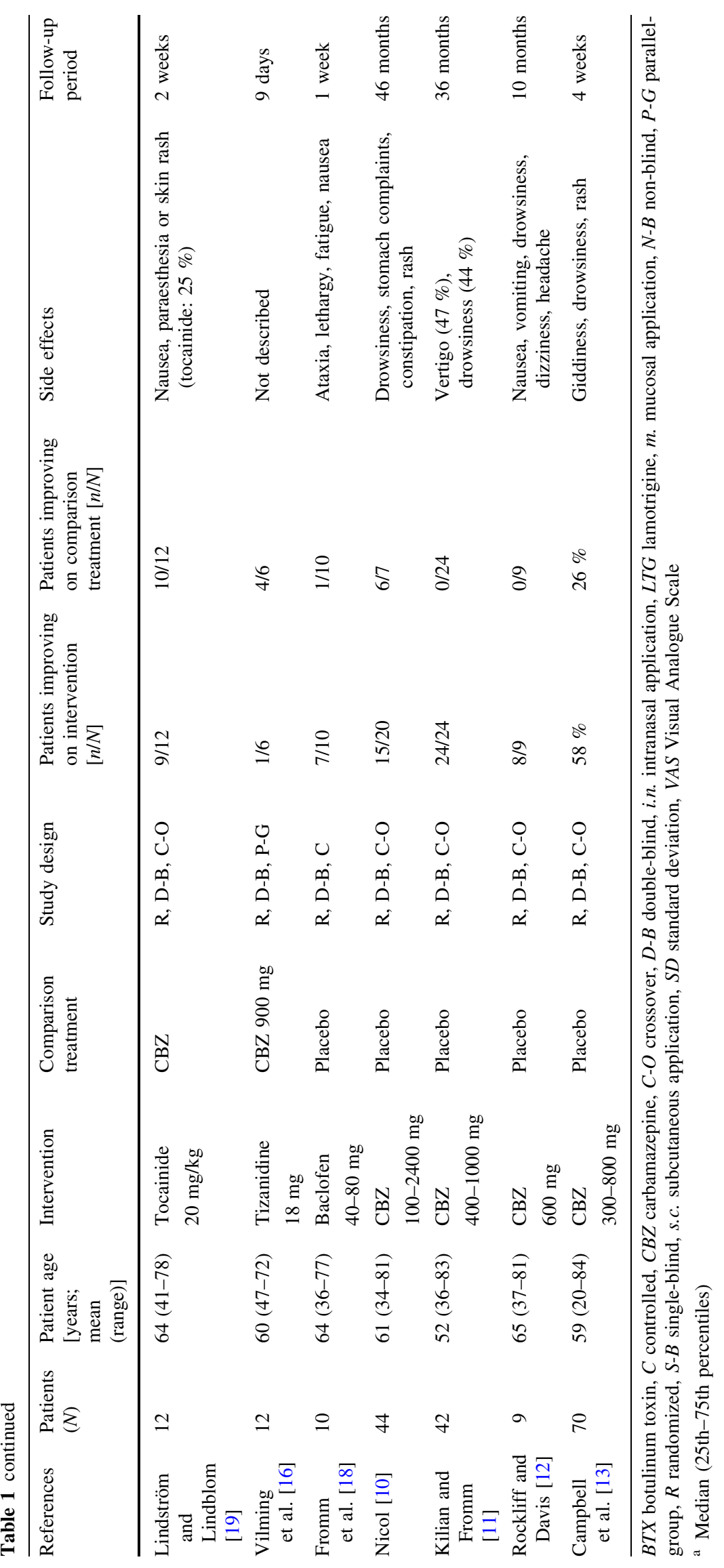


Table 2 Risks of bias in the included studies

\begin{tabular}{|c|c|c|c|c|c|}
\hline References & Randomization & $\begin{array}{l}\text { Allocation } \\
\text { concealment }\end{array}$ & $\begin{array}{l}\text { Double } \\
\text { blinding }\end{array}$ & $\begin{array}{l}\text { Handling } \\
\text { of dropouts }\end{array}$ & $\begin{array}{l}\text { Similarity of } \\
\text { groups at baseline }\end{array}$ \\
\hline Niki et al. [26] & $?$ & $?$ & + & + & + \\
\hline Shehata et al. [22] & + & + & - & + & + \\
\hline Zúñiga et al. [23] & + & + & + & + & + \\
\hline Wu et al. [24] & $?$ & $?$ & + & + & + \\
\hline Shaikh et al. [14] & - & - & - & + & + \\
\hline Kanai et al. [25] & $?$ & $?$ & $?$ & + & + \\
\hline Kanai et al. [27] & + & + & $?$ & + & + \\
\hline Zakrzewska et al. [15] & + & $?$ & + & + & + \\
\hline Kondziolka et al. [21] & + & + & + & + & + \\
\hline Fromm et al. [17] & $?$ & $?$ & + & + & $?$ \\
\hline Lechin et al. [20] & + & $?$ & + & + & + \\
\hline Lindström and Lindblom [19] & $?$ & $?$ & $?$ & + & - \\
\hline Vilming et al. [16] & $?$ & $?$ & $?$ & + & - \\
\hline Fromm et al. [18] & $?$ & $?$ & + & + & + \\
\hline Nicol [10] & + & $?$ & + & + & $?$ \\
\hline Kilian and Fromm [11] & + & $?$ & + & + & $?$ \\
\hline Rockliff and Davis [12] & + & + & + & + & $?$ \\
\hline Campbell et al. [13] & + & ? & + & $?$ & $?$ \\
\hline
\end{tabular}

+ risk of bias item handled correctly and described, - risk of bias item not handled correctly, ? not clear

statements on inclusion or exclusion of elderly patients with co-morbidities in the included studies. Therefore, the results of the trials cannot be extrapolated to the elderly population. Data concerning the efficacy/safety ratios of treatments for $\mathrm{TN}$ in the elderly are lacking in the literature.

According to the evidence in this review, the general first-line drug used in medical management of $\mathrm{TN}$ is still CBZ. If there are unacceptable side effects, which are mostly dose related and are more common in older patients, the patient should be switched to OXC [9]. Second-line treatment can be a combination of $\mathrm{CBZ}$ and lamotrigine or baclofen, but the evidence for the use of either combination is still weak. BTX type A administered subcutaneously could be effective, but the evidence for its use is weak as well. Local application of anaesthetics seems to be effective but only for a few hours. The authors of the current review propose an algorithm of evidence-based medical management of CTN (Fig. 2).

\subsection{Diagnostics in Trigeminal Neuralgia}

The diagnosis of CTN is mostly made on the basis of a clinical history and clinical examination. The diagnostic criteria suggested in the ICHD-3 [3] are at least three attacks occurring in one or more divisions of the trigeminal nerve, with no radiation beyond the trigeminal distribution.
The pain has at least three of the following four characteristics:

1. Recurring in paroxysmal attacks lasting from a fraction of a second to $2 \mathrm{~min}$.

2. Severe intensity.

3. Electric shock-like, shooting, stabbing or sharp in quality.

4. Precipitated by innocuous stimuli to the affected side of the face.

Furthermore, there is no clinically evident neurological deficit, and the pain cannot be attributed to another disorder.

Diagnosis of CTN in the elderly does not differ from that in younger patients, except that taking a clinical history from an elderly patient may be more challenging. TN caused by compression (vascular) is regarded as CTN. Vascular contact with cranial nerves is a normal variant found in many patients without TN [6]. Depending on the quality of imaging, MRI cannot be recommended for routine use, as it is currently too insensitive for detection of vascular compression of the trigeminal nerve [6, 9]. Trigeminal sensory deficits, bilateral involvement of the trigeminal nerve, an age at onset of $<40$ years, ophthalmic division only, deafness or other ear problems, and abnormal trigeminal reflexes are associated with an increased risk of STN and should be considered useful in distinguishing STN from CTN [6, 9]. In patients with $\mathrm{TN}$, 


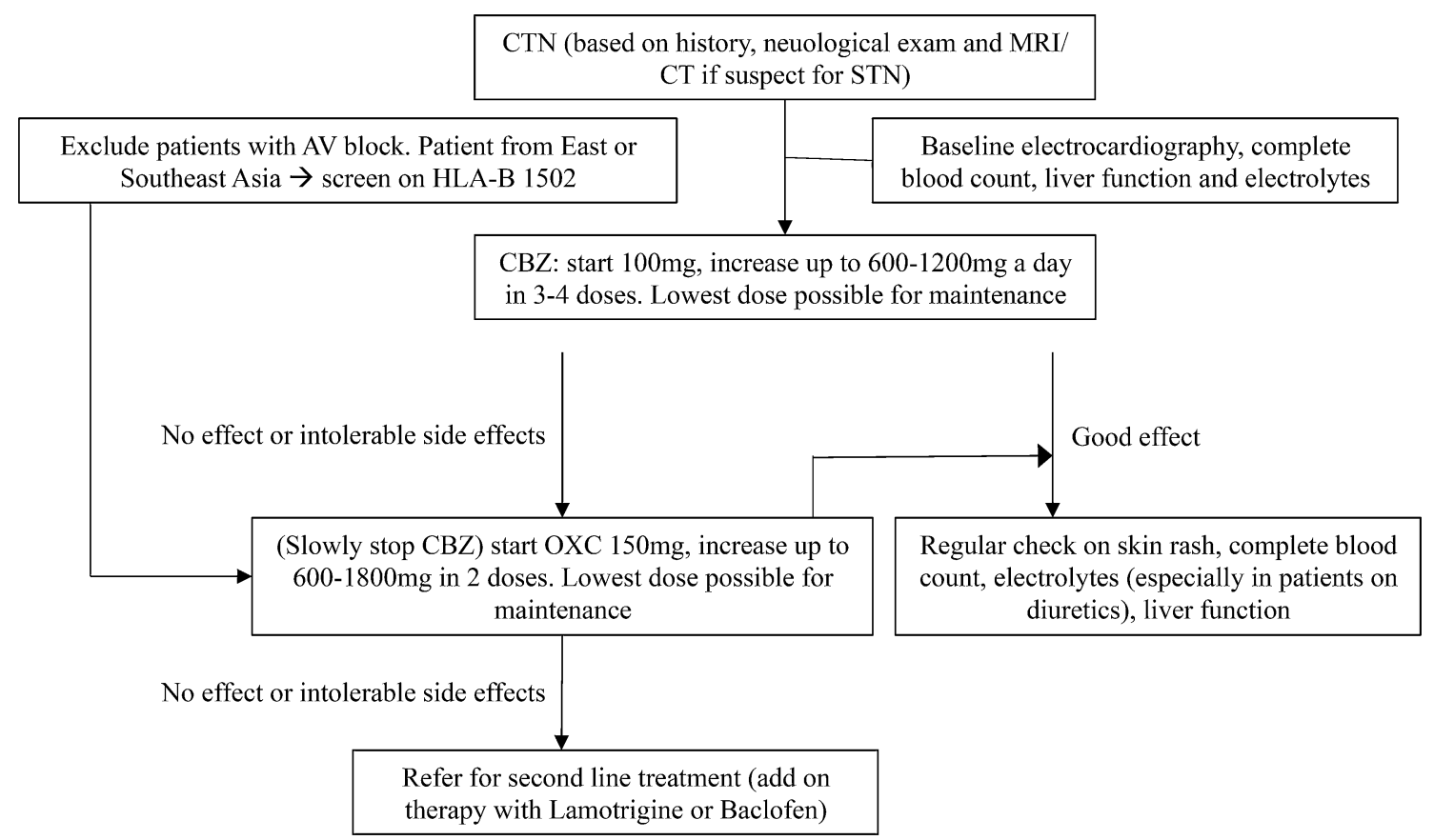

Fig. 2 Algorithm for medical management of classical trigeminal neuralgia $(\mathrm{CTN})$ in the elderly. $A V$ atrioventricular, $C B Z$ carbamazepine, $C T$ computed tomography, $H L A$ human leukocyte antigen,

routine head imaging identifies structural causes in up to $15 \%$ of patients and may be considered useful when STN is suspected.

\subsection{Adverse Events and Side Effects of Antiepileptics}

CBZ is the first choice for non-surgical management of TN. Side effects of CBZ include central nervous system (CNS) disturbances, such as a lack of balance, dizziness and somnolence, skin rash, renal dysfunction, leukopenia, elevation in liver transaminases, hyponatraemia, thrombocytopenia, accommodation disorders, ataxia, nausea and vomiting, cardiac arrhythmias and, in long-term use, osteoporosis and folate deficiency [28]. In a recent retrospective study in 200 patients treated with CBZ or OXC, $27 \%$ of patients treated with CBZ and $18 \%$ of patients treated with OXC incurred an adverse event that directly caused interruption of treatment [29]. The onset of side effects occurred with mean dosages of $600 \mathrm{mg}$ for CBZ and $1200 \mathrm{mg}$ for OXC. Most side effects occurred within the first month. CBZ treatment is usually initiated at $200 \mathrm{mg}$. After auto-induction, the dose often needs to be increased and titrated according to the clinical response. In the elderly, a starting dose of $100 \mathrm{mg}$ is advisable, especially because during auto-induction, the concentrations will go up fast even with lower doses [30]. Kutluay et al. [31] compared the safety and tolerability of OXC in a
MRI magnetic resonance imaging, $O X C$ oxcarbazepine, STN symptomatic trigeminal neuralgia

cohort of 52 patients aged $\geq 65$ years and a cohort of 1574 patients ranging in age between 18 and 64 years, and found that the tolerability in the older age group was similar to that in younger adults. Some important pre-treatment precautions should be taken when CBZ or OXC is being prescribed, such as baseline measurements of haematology, electrolytes and liver function [32]. During treatment, careful clinical observation is necessary to minimize the risks of interactions and adverse events, especially in the elderly. The UK National Institute for Health and Care Excellence (NICE) recommends a full blood count; measurement of electrolytes, liver enzymes and vitamin D levels; and other tests of bone metabolism (serum calcium and alkaline phosphatase) every 2-5 years in patients taking enzyme-inducing drugs [33].

\subsection{Interactions of Carbamazepine and Oxcarbazepine}

CBZ is an inducer of cytochrome $\mathrm{P} 450$ (CYP) $3 \mathrm{~A} 4$, which results in acceleration of the metabolism of concurrently prescribed antiepileptics, tricyclic antidepressants, antipsychotics, steroid oral contraceptives, glucocorticoids, oral anticoagulants, cyclosporine, theophylline, chemotherapeutic agents and cardiovascular drugs. Elevation of plasma CBZ concentrations to potentially toxic levels can be caused by macrolide antibiotics, metronidazole, some antidepressants, calcium-channel blockers and valproic acid [34]. In 
0.01-0.06 \% of Caucasian patients, CBZ-induced StevensJohnson syndrome (SJS)/toxic epidermal necrolysis (TEN) can occur. This percentage is approximately ten times higher in East Asian and South-East Asian populations because of their higher prevalence of the human leukocyte antigen (HLA)-B 1502 allele. Routine testing for this allele seems cost effective only in patients from a population with a high prevalence of the allele [35]. A positive test for the allele still demands appropriate clinical vigilance and patient management because of the test's sensitivity of $92 \%$ and negative predictive value of $98 \%$. The chemical structure of $\mathrm{OXC}$ is similar to that of CBZ. Although the evidence of efficacy is stronger for $\mathrm{CBZ}$ than for $\mathrm{OXC}$, the latter may pose fewer safety concerns $[9,36]$. CBZ is contra-indicated in patients with atrioventricular (AV) block.

\subsection{Special Recommendations for Antiepileptics in the Elderly}

Older people, in particular, are sensitive to CNS disturbances and the sedative effects of medications [37]. A lack of balance, dizziness, somnolence, ataxia and blurred vision are all risk factors for falling. Elderly patients often have co-morbidities, such as diseases of the kidneys, liver, heart and blood vessels. On top of these co-morbidities, there are physiological modifications associated with aging, which all make the serum concentrations of antiepileptics unpredictable. Furthermore, the effectiveness of other medications often used by older patients (e.g. anticoagulants, antidepressants and antipsychotics) can be reduced, and some medication often prescribed in the elderly (e.g. calcium-channel blockers and macrolide antibiotics) can elevate the plasma concentration of CBZ to a toxic level [37]. A quarter of patients taking more than one drug have been found to be candidates for drug-drug interactions [38]. To complicate prevention of drug-drug interactions even more, there is often a discrepancy in reported and true drug use [39]. As OXC is associated with fewer adverse events and fewer drug interactions than CBZ, and it seems to be as effective as CBZ, one could consider prescribing OXC in the elderly [36]. While switching from $\mathrm{CBZ}$ to $\mathrm{OXC}$, phase out the $\mathrm{CBZ}$ to prevent CBZ-associated withdrawal reaction [40]. As mentioned before, it is advisable to lower the initial doses of $\mathrm{CBZ}$ and $\mathrm{OXC}$ in the elderly to $100 \mathrm{mg}$ and $150 \mathrm{mg}$, respectively. A baseline complete blood count, electrolytes and liver function should be repeatedly measured during treatment.

\subsection{Agreements and Disagreements with Other Studies}

Cruccu and Truini [41] suggest following the AAN/EFNS guidelines on TN management, i.e. if a patient reaches the therapeutic dosage with either $\mathrm{CBZ}$ or OXC and does not have satisfactory pain relief, then the patient should be referred for surgery. For patients who are not eligible to undergo surgery, lamotrigine as add-on therapy or BTX injections should be tried. Lamotrigine and BTX type A injections may straightforwardly be regarded as an alternative to surgery, but the evidence is not yet strong enough [42]. Surgery is not always an option in elderly patients, particularly if they are not medically fit. If surgery is not contra-indicated, palliative destructive trigeminal nerve root procedures, such as radiofrequency lesioning, chemical destruction, balloon compression or stereotactic radiosurgery (Gamma Knife), should be considered over microvascular decompression because of the less invasive nature of these techniques. These palliative destructive trigeminal nerve root procedures tend to result in sensory side effects [43, 44]. A Cochrane review [45] assessed the effects of non-antiepileptic drugs in TN and concluded that there was insufficient evidence from the four included RCTs to show a significant benefit from nonantiepileptic drugs in TN. Another Cochrane review [6] investigating the efficacy of $\mathrm{CBZ}$ for acute and chronic pain concluded that CBZ was effective in chronic neuropathic pain, but $66 \%$ of participants experienced at least one adverse event, with somnolence and dizziness ratios of 40-60\%. Conversely, a Cochrane review on antiepileptic drugs for neuropathic pain from 2013 concluded that there was insufficient evidence of an effect for the use of CBZ [46].

\section{Conclusions}

For first-line treatment of TN, use of the algorithm presented in Fig. 2 is advised. Prescribe antiepileptics in the elderly with extreme caution, and pay attention to drugdrug interactions and side effects. In the literature, there is a deficiency of research on CTN in the elderly. Further research should focus on the efficacy and safety of the alternative non-surgical treatment options. Older patients and patients with co-morbidities and concomitant therapies should be included in the research population as well to allow generalization of research conclusions to 'real life'.

\section{Compliance with Ethical Standards}

Conflicts of interest Both authors (M. A. E.-M. Oomens and T. Forouzanfar) declare that they have no conflicts of interest.

Funding Both authors (M. Oomens and T. Forouzanfar) declare that they received no funding to support this manuscript.

Open Access This article is distributed under the terms of the Creative Commons Attribution-NonCommercial 4.0 International License (http://creativecommons.org/licenses/by-nc/4.0/), which permits any noncommercial use, distribution, and reproduction in any medium, provided you give appropriate credit to the original 
author(s) and the source, provide a link to the Creative Commons license, and indicate if changes were made.

\section{References}

1. Zakrzewska JM. Multi-dimensionality of chronic pain of the oral cavity and face. J Headache Pain. 2013;14(1):37.

2. Zakrzewska JM. Diagnosis and differential diagnosis of trigeminal neuralgia. Clin J Pain. 2002;18(1):14-21.

3. Headache Classification Committee of the International Headache Society (IHS). The international classification of headache disorders, 3rd edition (beta version. Cephalalgia. 2013;33(9):629-808.

4. Montano N, Connforti G, Di Bonaventura R, Meglio M, Fernandez E, Papacci F. Advances in diagnosis and treatment of trigeminal neuralgia. Ther Clin Risk Manag. 2015;24(11):289-99.

5. Zakrzewska JM, Linskey ME. Trigeminal neuralgia. BMJ. 2014;17(348):g474.

6. Wiffen PJ, Derry S, Moore RA, McQuay HJ. Carbamazepine for acute and chronic pain in adults. Cochrane Database Syst Rev. 2011;1:CD005451. doi:10.1002/14651858.CD005451.pub2.

7. Kugelberg E, Lindblom U. The mechanism of the pain in trigeminal neuralgia. $\mathrm{J}$ Neurol Neurosurg Psychiatry. 1959;22(1):36-43.

8. Eller JL, Raslan AM, Burchiel KJ. Trigeminal neuralgia: definition and classification. Neurosurg Focus. 2005;18(5):E3.

9. Gronseth G, Cruccu G, Alksne J, Argoff C, Brainin M, Burchiel K, Nurmikko T, Zakrzewska JM. Practice parameter: the diagnostic evaluation and treatment of trigeminal neuralgia (an evidence-based review): report of the Quality Standards Subcommittee of the American Academy of Neurology and the European Federation of Neurological Societies. Neurology. 2008;71(15):1183-90.

10. Nicol CF. A four year double-blind study of tegretol in facial pain. Headache. 1969;9(1):54-7.

11. Killian JM, Fromm GH. Carbamazepine in the treatment of neuralgia: use of side effects. Arch Neurol. 1968;19(2):129-36.

12. Rockliff BW, Davis EH. Controlled sequential trials of carbamazepine in trigeminal neuralgia. Arch Neurol. 1966;15(2):129-36.

13. Campbell FG, Graham JG, Zilkha KJ. Clinical trial of carbazepine (tegretol) in trigeminal neuralgia. J Neurol Neurosurg Psychiatry. 1966;29(3):265-7.

14. Shaikh S, Yaacob HB, Abd Rahman RB. Lamotrigine for trigeminal neuralgia: efficacy and safety in comparison with carbamazepine. J Chin Med Assoc. 2011;74(6):243-9.

15. Zakrzewska JM, Chaudhry Z, Nurmikko TJ, Patton DW, Mullens EL. Lamotrigine (lamictal) in refractory trigeminal neuralgia: results from a double-blind placebo controlled crossover trial. Pain. 1997;73(2):223-30.

16. Vilming ST, Lyberg T, Lataste $X$. Tizanidine in the management of trigeminal neuralgia. Cephalalgia. 1986;6(3):181-2.

17. Fromm GH, Aumentado D, Terrence CF. A clinical and experimental investigation of the effects of tizanidine in trigeminal neuralgia. Pain. 1993;53(3):265-71.

18. Fromm GH, Terrence CF, Chattha AS. Baclofen in the treatment of trigeminal neuralgia: double-blind study and long-term followup. Ann Neurol. 1984;15(3):240-4.

19. Lindström $P$, Lindblom $U$. The analgesic effect of tocainide in trigeminal neuralgia. Pain. 1987;28(1):45-50.

20. Lechin F, van der Dijs B, Lechin ME, Amat J, Lechin AE, Cabrera A, et al. Pimozide therapy for trigeminal neuralgia. Arch Neurol. 1989;46(9):960-3.
21. Kondziolka D, Lemley T, Kestle JR, Lunsford LD, Fromm GH, Jannetta PJ. The effect of single-application topical ophthalmic anesthesia in patients with trigeminal neuralgia: a randomized double-blind placebo-controlled trial. J Neurosurg. 1994;80(6):993-7.

22. Shehata HS, El-Tamawy MS, Shalaby NM, Ramzy G. Botulinum toxin-type A: could it be an effective treatment option in intractable trigeminal neuralgia? $J$ Headache Pain. 2013;19(14):92.

23. Zúñiga C, Piedimonte F, Díaz S, Micheli F. Acute treatment of trigeminal neuralgia with onabotulinum toxin A. Clin Neuropharmacol. 2013;36(5):146-50.

24. Wu CJ, Lian YJ, Zheng YK, Zhang HF, Chen Y, Xie NC, Wang LJ. Botulinum toxin type A for the treatment of trigeminal neuralgia: results from a randomized, double-blind, placebo-controlled trial. Cephalalgia. 2012;32(6):443-50.

25. Kanai A, Saito M, Hoka S. Subcutaneous sumatriptan for refractory trigeminal neuralgia. Headache. 2006;46(4):577-82 (discussion 583-4).

26. Niki Y, Kanai A, Hoshi K, Okamoto H. Immediate analgesic effect of $8 \%$ lidocaine applied to the oral mucosa in patients with trigeminal neuralgia. Pain Med. 2014;15(5):826-31.

27. Kanai A, Suzuki A, Kobayashi M, Hoka S. Intranasal lidocaine $8 \%$ spray for second-division trigeminal neuralgia. Br J Anaesth. 2006;97(4):559-63.

28. Reisner L, Pettengill CA. The use of anticonvulsants in orofacial pain. Oral Surg Oral Med Oral Pathol Oral Radiol Endod. 2001;91(1):2-7.

29. Di Stefano G, La Cesa S, Truini A, Cruccu G. Natural history and outcome of 200 outpatients with classical trigeminal neuralgia treated with carbamazepine or oxcarbazepine in a tertiary centre for neuropathic pain. J Headache Pain. 2014;9(15):34.

30. Beydoun A. Clinical use of tricyclic anticonvulsants in painful neuropathies and bipolar disorders. Epilepsy Behav. 2002;3(3S):S18-22.

31. Kutluay E, McCague K, D’Souza J, Beydoun A. Safety and tolerability of oxcarbazepine in elderly patients with epilepsy. Epilepsy Behav. 2003;4(2):175-80.

32. Sindrup SH, Jensen TS. Pharmacotherapy of trigeminal neuralgia. Clin J Pain. 2002;18(1):22-7.

33. National Institute for Health and Care Excellence [NICE]. The epilepsies: the diagnosis and management of the epilepsies in adults and children in primary and secondary care. NICE clinical guideline 137. NICE. 2012. https://www.nice.org.uk/guidance/ cg137/resources/guidance-the-epilepsies-the-diagnosis-andmanagement-of-the-epilepsies-in-adults-and-children-in-primaryand-secondary-care-pdf. Accessed 8 Aug 2015.

34. Spina E, Pisani F, Perucca E. Clinically significant pharmacokinetic drug interactions with carbamazepine: an update. Clin Pharmacokinet. 1996;31(3):198-214.

35. Locharernkul C, Shotelersuk V, Hirankarn N. Pharmacogenetic screening of carbamazepine-induced severe cutaneous allergic reactions. J Clin Neurosci. 2011;18(10):1289-94.

36. Beydoun A, Schmidt D, D'Souza J. Oxcarbazepine versus carbamazepine in trigeminal neuralgia: a meta-analysis of three double blind comparative trails. Neurology. 2002;58((Suppl 3)):02.083.

37. Seymour RM, Routledge PA. Important drug-drug interactions in the elderly. Drugs Aging. 1998;12(6):485-94.

38. Tulner LR, Frankfort SV, Gijsen GJ, van Campen JP, Koks CH, Beijnen JH. Drug-drug interactions in a geriatric outpatient cohort: prevalence and relevance. Drugs Aging. 2008;25(4):343-55.

39. Tulner LR, Kuper IM, Frankfort SV, van Campen JP, Koks CH, Brandjes DP, Beijnen JH. Discrepancies in reported drug use in geriatric outpatients: relevance to adverse events and drug-drug interactions. Am J Geriatr Pharmacother. 2009;7(2):93-104. 
40. Chen MJ, Zhang WJ, Guo ZL, Zhang WH, Chai Y, Li YW. Withdrawal reaction of carbamazepine after neurovascular decompression for trigeminal neuralgia: a preliminary study. J Neurol Sci. 2014;338(1-2):43-5.

41. Cruccu G, Truini A. Refractory trigeminal neuralgia: non-surgical treatment options. CNS Drugs. 2013;27(2):91-6.

42. Wiffen PJ, Derry S, Moore RA. Lamotrigine for chronic neuropathic pain and fibromyalgia in adults. Cochrane Database Syst Rev. 2013;12:CD006044. doi:10.1002/14651858.CD006044. pub4.

43. Zakrzewska JM, Akram H. Neurosurgical interventions for the treatment of classical trigeminal neuralgia. Cochrane Database Syst Rev. 2011;9:CD007312. doi:10.1002/14651858.CD007312. pub2.
44. Zakrzewska JM, Coakham HB. Microvascular decompression for trigeminal neuralgia: update. Curr Opin Neurol. 2012;25:296-301.

45. Zhang J, Yang M, Zhou M, He L, Chen N, Zakrzewska JM. Nonantiepileptic drugs for trigeminal neuralgia. Cochrane Database Syst Rev. 2013;12:CD004029. doi:10.1002/14651858. CD004029.pub4.

46. Wiffen PJ, Derry S, Moore RA, Aldington D, Cole P, Rice AS, Lunn MP, Hamunen K, Haanpaa M, Kalso EA. Antiepileptic drugs for neuropathic pain and fibromyalgia-an overview of Cochrane reviews. Cochrane Database Syst Rev. 2013;11:CD010567. doi:10.1002/14651858.CD010567.pub2. 